\title{
FUNCTIONAL ADAPTATIONS OF THE RIGHT VENTRICULAR OUTFLOW TRACT IN CONGENITAL HEART DISEASE
}

\author{
BY \\ HAMISH WATSON AND K. G. LOWE \\ From the Department of Medicine in the University of St. Andrews, Queen's College, Dundee \\ Received September 11, 1964
}

Despite intensive study in recent years, the natural history of many congenital heart lesions remains far from fully resolved, and it is only now becoming generally appreciated that physical forces as well as structural abnormalities may greatly influence their evolution both before and after birth. Nadas (1957) has pointed out, for example, that some malformations which can be identified in the newborn period do not assume their full pathognomonic features till months or even years later, and Wood (1962) in one of his last papers, re-emphasized his view that atrial septal defects normally behaved in this way.

It is, however, also true that functional modifications may so alter the clinical picture in some other lesions that their early clinical identity is later almost completely lost. Such changes, the end result of a complex interplay of forces affecting the right ventricular outflow tract and the pulmonary arteriolar bed, are most often seen in conditions that alter the volume and pressure of blood flowing through the right side of the heart and the lesser circulation.

Attention was probably first focused on the importance of the right ventricular outflow tract with the realization that the infundibular obstruction so often seen in severe isolated pulmonary valvular stenosis was due to muscular hypertrophy (Kirklin et al., 1953; Blount et al., 1954; Brock, 1955). Though there is as a rule no conventional systolic pressure gradient in this type of infundibular stenosis because the outflow tract is reduced in diameter over its whole length (Watson et al., 1960), it can usually be detected on careful catheter withdrawal by the shape of the infundibular pressure pulse which shows a fall in pressure during systole as the blood travels with increased velocity along the narrowed lumen (Watson and Lowe, 1962; Watson, Breckenridge, and Lowe, 1964).

Just as these studies of pressure flow relations in pulmonary stenosis have demonstrated the presence of obstruction without obvious pressure gradients, so others (Blount et al., 1954; Rudolph, Nadas, and Goodale, 1954; Shephard, 1954; Kjellberg et al., 1955) have demonstrated pressure gradients in the absence of demonstrable organic obstruction. Differences of $20 \mathrm{~mm}$. $\mathbf{H g}$ or more between the pulmonary arterial and right ventricular systolic pressures, for example, are commonly seen in patients whose only lesions are atrial septal defects. These gradients are now generally accepted as a sign of relative pulmonary stenosis caused by increased blood flow through normal valves, since no evidence of stenosis is found when such hearts are examined at operation or necropsy. One puzzling feature, however, is that in many cases the gradient bears little relation to the volume of the left-to-right shunt, and it may well be that its magnitude for any given flow varies with the distensibility of the pulmonary valve ring. Rudolph and his colleagues (1954) have also suggested that where high systolic pressure gradients are recorded, a mild degree of true pulmonary valvular stenosis may coexist with the defect in the interatrial septum. 
It is very difficult to determine whether or not minor degrees of organic pulmonary stenosis are present in such cases, even after a careful inspection of the valve. In some cases there are thickened cusps but no diminution of valve area and in others the cusps seem normal though the orifice may be slightly reduced in size. In the case illustrated, for example, in Fig. 1, which shows a tracing made as a catheter was withdrawn from the pulmonary artery into mid-cavity right ventricle, the pulmonary valve was examined through a transarterial incision after a secundumtype atrial septal defect had been closed in a 5-year-old girl, and despite the fact that the cusps were thin, mobile, and appeared healthy, a mild degree of pulmonary valvular stenosis was reported because the valve ring was thought to be too narrow for a child of this age

Whatever their nature, it is clear from a correlation of simultaneously recorded pressure pulses and intracardiac electrograms (Watson, 1964) that in the great majority of uncomplicated atrial septal defects these gradients occur at the pulmonary valve. Though Shephard (1954)

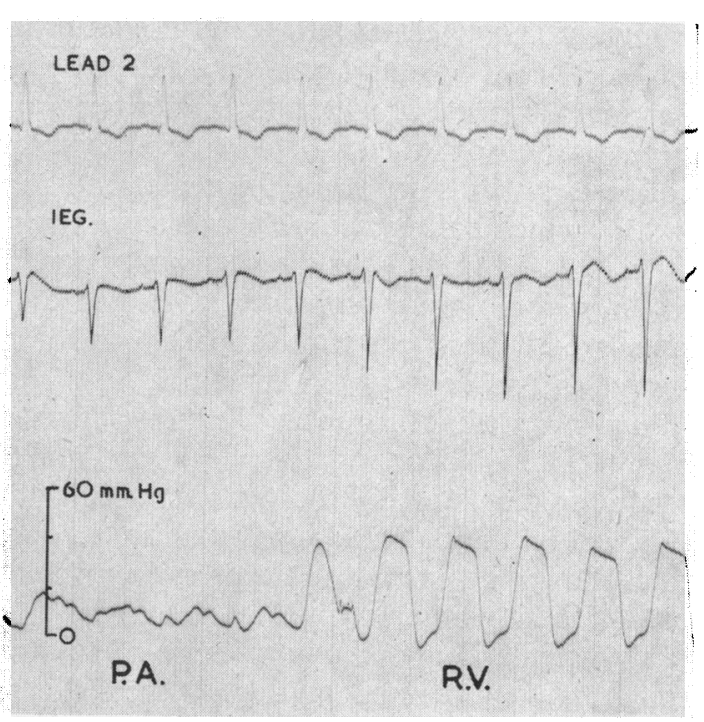

FIG. 1.-Pressure recording during withdrawal from the pulmonary artery (P.A.) to the right ventricle (R.V.) with simultaneous intracardiac electrocardiogram (IEG.) in a case of ostium secundum defect. It shows a systolic pressure gradient at the pulmonary valve. reported gradual changes in the pressure pulse on withdrawal, which were quite unlike the sudden pressure gradients seen in pulmonary valvular stenosis, and Johnson (1959) has found evidence of contractile infundibular stenosis in cases of atrial septal defect, we have not observed such variations in the infundibular pressure pulse, and, in the absence of an obvious valvular lesion or right ventricular hypertension, our experience has also been that cine-angiocardiographic studies seldom show anything other than a widely dilated right ventricular outflow tract.

Though simple flow gradients are also seen in patients with defects in the interventricular septum, large flows through such lesions sometimes provoke much more complex changes in the right ventricular outflow tract and systolic pressure gradients have been shown to appear in the infundibulum. Taussig first suggested, in 1955, that left-to-right shunting through large ventricular septal defects might be reduced when the lumen of the outflow tract became narrowed by right ventricular hypertrophy. Her clinical impression was later confirmed by serial catheter studies when Gasul and his colleagues (1957) made their remarkable discovery that gradually acquired infundibular stenosis in some such infants so transformed the clinical picture that it became virtually indistinguishable from that seen in Fallot's tetralogy.

Several different types of pressure gradient may be seen in association with ventricular septal defects, and according to Brotmacher and Campbell (1958) about 10 per cent of all cases with left-toright shunts have associated pulmonary stenosis of one sort or another. They recorded 15 patients in their series who had systolic pressure gradients, mostly infundibular, of between 35 and $100 \mathrm{~mm}$. Hg. Until recently, however, most hæmodynamic studies have been carried out on older children and adults, and in the absence of data from serial cardiac catheterization, it has not been possible to say with any degree of certainty whether such outflow tract obstruction was congenital or acquired - even with the help of necropsy. Bloomfield (1964), in an attempt to define the natural history of ventricular septal defects in patients surviving infancy, has analysed a large series of 424 cases and though only 10 of these had had serial hæmodynamic studies, he reports the development of a large infundibular pressure gradient in one. This, which he claims has not previously been observed in adults, was recorded during the fifth decade in a woman who had formerly shown only a mild pulmonary valvular stenosis. 
Summarizing their experience of the natural history of ventricular septal defects in infancy and childhood based on serial catheter studies, Lynfield $e t$ al. (1961) report 4 cases of acquired infundibular stenosis in all of whom there had been an opportunity to examine the anatomy of the right ventricular outflow tract. Each showed hypertrophy of the crista supraventricularis; in 3 this was associated with distortion of the septal and parietal muscle bands resembling that seen in Fallot's tetralogy which had presumably caused obstruction as the muscle mass increased; in the fourth it was an isolated finding causing deformity and narrowing of the infundibulum. The pre-operative systolic pressure gradient in this case was only $45 \mathrm{~mm}$. $\mathrm{Hg}$, and since the gradient had almost disappeared three weeks after simple closure of the ventricular septal defect, they concluded that the obstruction had been largely functional.

Pulmonary stenosis is even commoner in ventricular septal defect when there is associated aortic regurgitation. Nadas and his colleagues (1964) found that about half of their 34 cases had significant pressure gradients across the right ventricular outflow tract. The stenosis was infundibular in 10, combined infundibular and valvular in 1, and undetermined in 5 cases. Serial hæmodynamic studies showed an increase in the pressure gradient in about half the cases, but no constant anatomical basis for these gradients could be detected. In some there was moderate hypertrophy of the crista supraventricularis, and in one prolapse of an enormously ballooned right coronary aortic valve cusp through the ventricular septal defect seemed a possible explanation.

Various types of outflow tract obstruction may, therefore, develop in those who are born with ventricular septal defects, and an example of one in an infant who first presented with symptoms due to gross pulmonary hypertension is illustrated in Fig. 2 and 3. He was born in March 17, 1955 and had a characteristic history of recurrent respiratory infections and failure to thrive. When first seen aged 22 months he weighed only $18 \frac{1}{2} \mathrm{lb}$. $(8.62 \mathrm{~kg}$.) and had a large heart with grossly plethoric lung fields. At cardiac catheterization on February 11, 1957 he was found to have a systemic pressure in his pulmonary artery and a large left-to-right shunt at ventricular level. Fig. 2 shows a tracing made as an electrode-tipped catheter was withdrawn from the pulmonary trunk into the right ventricle and from there, after a pause to eliminate 50 cycle interference, into the right atrium. It demonstrates, despite pressure damping, that both pulmonary arterial and right ventricular hypertension were present at that time. He was managed along standard medical lines and when cardiac catheterization was repeated five years later on May 29, 1962 before surgical closure of the defect, it was found that a considerable systolic pressure gradient had developed across the right ventricular outflow tract during the interval between the two investigations. This is illustrated in Fig. 3 on a withdrawal tracing from pulmonary artery to right atrium, where it can be seen from the intracardiac electrogram that the obstruction was fairly low in the infundibulum. It was also noted at the second cardiac catheterization that the left-to-right shunt had become very considerably reduced and the pulmonary/systemic flow ratio on this occasion was only 1.4 to 1 . Despite the sustained right ventricular hypertension, the pulmonary vascular resistance was only 4 units and there was no arterial desaturation at rest. A large defect in the interventricular septum was closed on October 22, 1963, using cardio-pulmonary bypass, and a search was made for the "pulmonary stenosis". No obstructive lesion of any kind could be demonstrated on either inspection or palpation of the outflow tract of the right ventricle or at the pulmonary valve. At the end of the operation the right ventricular pressure had returned almost to within normal limits, and no significant systolic pressure gradient could be detected.

This case is in sharp contradistinction to another remarkable case, that of C. Bruins (personal communication to Engle, Ehlers, and Ito (1964)), where a ventricular septal defect in a baby with a large left-to-right shunt underwent spontaneous closure later in childhood. She had, however, in the meantime developed infundibular stenosis of such severity that surgical resection was required for its relief.

There is ample evidence from studies in other organs to support the concept of a physiological sphincter in the right ventricular outflow tract, even in the absence of its anatomical exhibition (R. Walmsley, 1964, personal communication). This example of acquired infundibular stenosis is 


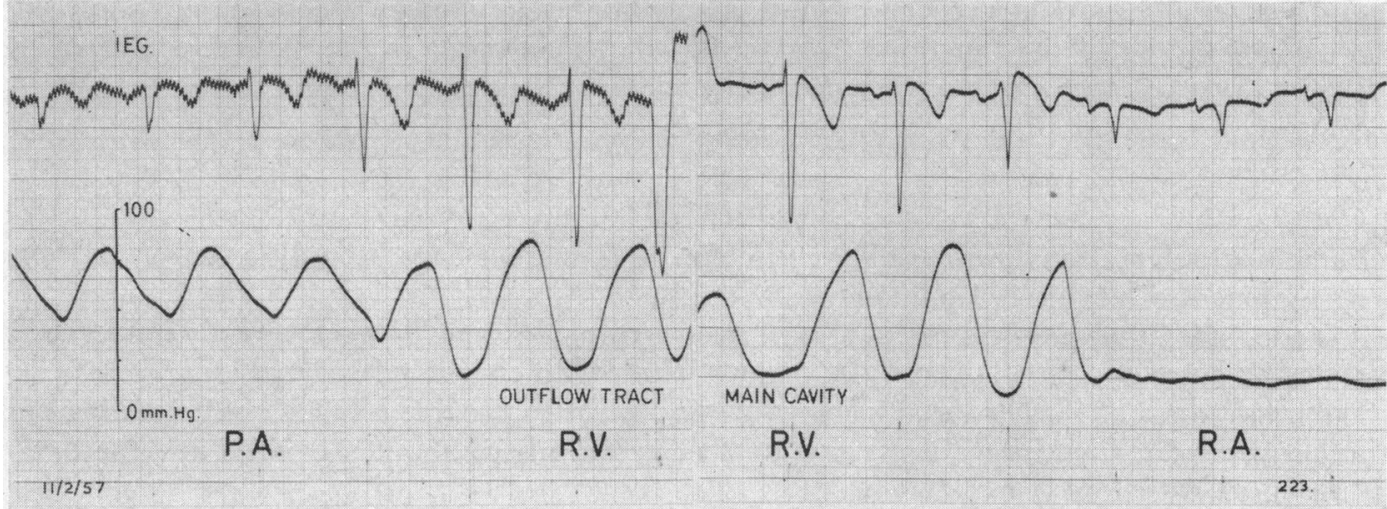

FIG. 2.-Pressure recording made with an electrode tipped catheter during withdrawal from the pulmonary artery (P.A.) to the right ventricle (R.V.) and right atrium (R.A.) in an infant with a large ventricular septal defect. There was a torrential left-to-right shunt and both pulmonary arterial and right ventricular hypertension. IEG.-intracardiac electrocardiogram.

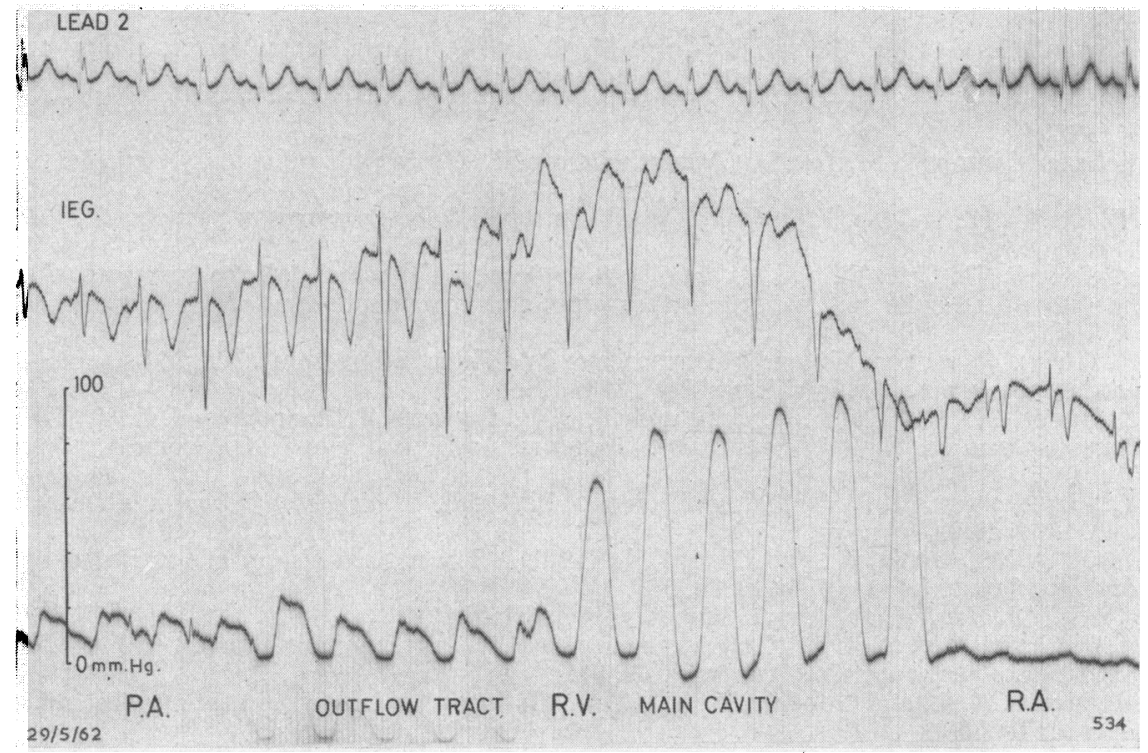

Fig. 3.-Same patient as in Fig. 2 five years later. Withdrawal pressure tracing from pulmonary artery (P.A.) to right ventricle (R.V.) and right atrium (R.A.) with simultaneous intracardiac electrocardiogram (IEG.), showing that severe stenosis has developed at the lower end of the outflow tract of the right ventricle. No obstructive lesion of any kind was found either in the infundibulum or at the pulmonary valve when the ventricular septal defect was closed using cardio-pulmonary bypass.

yet another link in the fascinating chain of evidence that is now revealing the variations that may take place in the life history of infants with a large ventricular septal defect. Recent reviews by Wade and Wright (1963) and by Arcilla et al. (1963) have demonstrated that it may alter relatively quickly during the first few years of life. Though the development of infundibular stenosis protects the pulmonary vasculature from the effects of torrential blood flow in much the same manner as the surgical procedure of banding of the pulmonary trunk, we have as yet little idea of the frequency of this reaction. 
Further serial hæmodynamic and cine-angiocardiographic studies are required to provide a fuller understanding of the functional adaptations that may occur in the natural course of these congenital heart lesions, so that we may give better advice about prognosis and the optimal time for surgical treatment should this prove to be necessary.

\section{SUMMARY}

Functional adaptations in the right ventricular outflow tract have been discussed in relation to the development of acquired "pulmonary stenosis".

It is concluded that physical forces as well as structural abnormalities may greatly influence both the clinical picture and the life history of many patients with congenital heart lesions.

The importance of further serial hæmodynamic studies to provide a fuller understanding of the natural course of many lesions is stressed, so that better advice about prognosis and the optimal time for surgical treatment may be given.

\section{REFERENCES}

Arcilla, R. A., Agustsson, M. H., Bicoff, J. P., Lynfield, J., Weinberg, M., Jr., Fell, E. H., and Gasul, B. M. (1963). Further observations on the natural history of isolated ventricular septal defects in infancy and childhood. Circulation, 28, 560.

Bloomfield, D. K. (1964). The natural history of ventricular septal defect in patients surviving infancy. Circulation, $29,914$.

Blount, S. G., Swan, H., Gensini, G., and McCord, M. C. (1954). Atrial septal defect: clinical and physiologic response to complete closure in 5 patients. Circulation, 9,801 .

Brock, R. (1955). Control mechanisms in the outflow tract of the right ventricle in health and disease. Guy's Hosp. Rep., 104, 356.

Brotmacher, L., and Campbell, M. (1958). Ventricular septal defects with pulmonary stenosis. Brit. Heart J., $20,379$.

Engle, M. A., Ehlers, K. H., and Ito, T. (1964). Ventricular septal defect: progress of past decade. Advanc. Pediat., 13,65 .

Gasul, B. M., Dillon, R. F., Vrla, V., and Hait, G. (1957). Ventricular septal defects: their natural transformation into those with infundibular stenosis or into the cyanotic or noncyanotic type of tetralogy of Fallot. J.Amer. med. Ass., 164, 847.

Johnson, A. M. (1959). Functional infundibular stenosis: its differentiation from structural stenosis and its importance in atrial septal defect. Guy's Hosp. Rep., 108, 373.

Kirklin, J. W., Connolly, D. C., Ellis, F. H., Jr., Burchell, H. B., Edwards, J. E., and Wood, E. H. (1953). Problems in the diagnosis and surgical treatment of pulmonic stenosis with intact ventricular septum. Circulation, 8,849 .

Kjellberg, S. R., Mannheimer, E., Rudhe, U., and Jonsson, B. (1955). Diagnosis of Congenital Heart Disease. The Year Book Publications, Chicago.

Lynfield, J., Gasul, B. M., Arcilla, R., and Luan, L. L. (1961). The natural history of ventricular septal defects in infancy and childhood. Amer. J. Med., 30, 357.

Nadas, A. S. (1957). Pediatric Cardiology. Saunders, Philadelphia.

-, Thilenius, O. G., LaFarge, C. G., and Hauck, A. J. (1964). Ventricular septal defect with aortic regurgitation. Medical and pathologic aspects. Circulation, $29,862$.

Rudolph, A. M., Nadas, A. S., and Goodale, W. T. (1954). Intracardiac left-to-right shunts with pulmonic stenosis. Amer. Heart J., 48, 808 .

Shephard, R. J. (1954). Pulmonary arterial pressure in acyanotic congenital heart disease. Brit. Heart J., $16,361$.

Taussig, H. B. (1955). Left-to-right shunts in infancy. In Henry Ford Hosp.: International Symposium on Cardiovascular Surgery, ed. C. R. Lam, p. 119. Saunders, Philadelphia.

Wade, G., and Wright, J. P. (1963). Spontaneous closure of ventricular septal ¿afects. Lancet, $1,737$.

Watson, H. (1964). Electrode catheters and the diagnostic application of intracardiac electrography in small children. Circulation, 29, 284.

- , Breckenridge, A. M., and Lowe, K. G. (1964). Right ventricular pressure flow relationships and intracardiac Venturi effects in Fallot's tetralogy. Brit. Heart J., 26, 794.

—, and Lowe, K. G. (1962). Ventricular pressure flow relationships in isolated pulmonary valvular stenosis. Brit. Heart J., 24, 431.

- , Pickard, C., Lowe, K. G., and Hill, I. G. W. (1960). Cine-angiocardiographic studies of the outflow tract in isolated pulmonary valvular stenosis. Brit. Heart J., 22, 706.

Wood, P. (1962). Fate of the child with unrelieved congenital heart disease: atrial septal defect. In Congenital Heart Disease: An International Symposium, ed. D. P. Morse, p. 49 . Blackwell Scientific Publications, Oxford. 